\title{
Frequency of Disturbed Defecation Pattern in Neurosurgical Critically Ill Patients and Influence on Intracranial Pressure and Intensive Care Treatment
}

\author{
Martin Kieninger $^{1^{\star}}$, Tobias Finzel ${ }^{1}$, Nina Zech ${ }^{1}$, Milena Seemann $^{2}$, Sylvia Bele ${ }^{3}$ and Holger Künzig ${ }^{1}$ \\ ${ }^{1}$ Department of Anesthesiology, University Hospital Regensburg, Germany \\ ${ }^{2}$ Department of Anesthesiology, Klinikum Nürnberg, Germany \\ ${ }^{3}$ Department of Neurosurgery, University Hospital Regensburg, Germany \\ *Corresponding author: Martin Kieninger, Department of Anesthesiology, University Hospital Regensburg, Germany, Tel: +49-941-9440; E-mail: \\ martin.kieninger@ukr.de
}

Received date: Aug 31, 2015; Accepted date: Dec 20, 2015; Published date: Dec 28, 2015

Copyright: ( 2015 Kieninger M, et al. This is an open-access article distributed under the terms of the Creative Commons Attribution License, which permits unrestricted use, distribution, and reproduction in any medium, provided the original author and source are credited.

\begin{abstract}
Background: Inadequate bowel movement is a common problem in intensive care patients. Aim of this study was to quantify the frequency of disturbed defecation pattern in critical ill neurosurgical patients and examine the influence on intracranial pressure (ICP) and treatment on intensive care unit (ICU).

Patients and Methods: Data were collected retrospectively during treatment on a neurosurgical ICU over a period of three years. Daily bowel movement was regarded to be sufficient when stool volume was more than $150 \mathrm{ml}$ liquid or mushy stool or the patient produced enough formed stool. Patients were classified into group "adequate defecation" when no period of more than three consecutive days without sufficient bowel movement was seen during ICU treatment or into group "inadequate defecation" respectively. A third group was built with patients showing constipation on seven consecutive days or longer.
\end{abstract}

Results: In a total of 73 recorded patients, 11 showed an adequate defecation pattern. Within the first ten days of ICU stay mean daily ICP values did not differ. However, patients with inadequate defecation had to be ventilated mechanically significantly longer ( 15.9 vs. 8.8 days) and had a significant longer need for ICU treatment ( 24.8 vs. 15.6 days). The mean cumulative dose of sedatives, sufentanil and norepinephrine was significantly higher in patients showing inadequate defecation. However, even long periods of constipation were not associated with a clinically relevant increase of ICP.

Conclusion: Neurosurgical ICU patients often show constipation. This does not cause elevated ICP values compared to patients without constipation. Disturbed bowel movement is associated with higher dosage of analgosedation and vasopressor therapy. Patients without constipation have to be ventilated less long and can be discharged from ICU earlier.

Keywords: Bowel movement; Defecation; Constipation; Intracranial pressure; Neurosurgical intensive care

\section{Introduction}

Motility disorders and disturbed defecation pattern seem to have impact on the development of increased ICP in patients with brain injury. Various reasons as e.g., prolonged periods of analgosedation, as often necessary after traumatic brain injury (TBI) or subarachnoid hemorrhage (SAH) may lead to insufficient bowel movement and even a state resembling paralytic ileus. This can result in an increase in intra-abdominal pressure (IAP) and potentially an increased intracranial pressure (ICP) [1-3]. In addition, an insufficient defecation rate is possibly associated with prolonged ventilation, increased rate of bacterial infection and a higher mortality rate [4-10].

Recently we could show that the implementation of a standard operating procedure (SOP) for treatment of constipation on a ICU increased the stool frequency but had no impact on ICP [11]. The aim of the following study was therefore to evaluate the effects of bowel movements per se on ICP and length of respirator dependency or ICU stay in patients with an acute serious cerebral disorder.

\section{Patients and Methods}

The study was approved and conducted according to the ethical care committee of the University of Regensburg (approval number 12-101-0240).

Criteria for being included into this study were an age older than 18 years, a severe brain injury such as TBI, SAH, intracerebral hemorrhage $(\mathrm{ICH})$ or other serious cerebral disorders and the necessity of continuous ICP monitoring, continuous analgosedation and invasive ventilation for more than three days. Exclusion criteria were pregnancy and severe gastro-intestinal diseases. Data from all patients who had met these criteria and had been treated on the neurosurgical ICU of the University Hospital Regensburg within a period of three years between January 2011 and December 2013 were collected retrospectively. 
Citation: Kieninger M, Finzel T, Zech N, Seemann M, Bele S, et al. (2015) Frequency of Disturbed Defecation Pattern in Neurosurgical Critically III Patients and Influence on Intracranial Pressure and Intensive Care Treatment. J Anesth Clin Res 6: 588. doi: $10.4172 / 2155-6148.1000588$

Page 2 of 5

For each day of ICU treatment the following data were extracted from the patient data management system (PDMS, MetaVision SuiteTM, iMDsoft, Tel Aviv, Israel): gut motility parameters, dose of drugs for analgosedation and circulatory-support (mean total dose during ICU treatment), ICP-levels (mean daily values), duration of mechanical ventilation and length of ICU stay.

Nutritional support was given according to the guidelines of the German Society for Nutrition (DGEM 2007, www.dgem.de) and the European Society for Clinical Nutrition and Metabolism (ESPEN 2005; www.espen.org). To improve defecation pattern physical therapy and pro motility drugs (mainly bisacodyl, lactulose, clyster, enteral given naloxone, sodium picosulfate, rhizine oil and neostigmine) were given following clinical assessment and the attending physician's estimation.

The defecation pattern was recorded separately for each day of ICU stay $(0.00$ am to $11.59 \mathrm{pm})$. Stool volume was measured using a fecal collector (FlexiSeal TM, ConvaTec, Munich, Germany) when patients had liquid or soft, mushy stool. In patients who had formed stool the classification in being enough or too few for a day was done corresponding to the assessment by the attending nurse. A cumulative stool volume of more than $150 \mathrm{ml}$ per day or enough formed stool for a day as documented in the PDMS was regarded to be a sufficient defecation. According to this, patients were initially divided into two groups: patients who had not shown a period of more than three consecutive days without sufficient bowel movement were classified into group "adequate defecation", patients with periods of more than three consecutive days with constipation into group "inadequate defecation". In addition, patients with episodes of insufficient bowel movement on at least seven consecutive days were classified into group "long period with inadequate defecation" and recorded separately.

Statistical analysis was performed using IBM SPSS Statistics TM Version 22 (IBM, Armonk, USA). Categorical data were displayed according to the distribution frequency. Statistical significance was calculated using chi-square test. Metric data were analyzed using Student's t-test when data were normally distributed or MannWhitney U test when not. Significance was supposed when $p$-value was $<0.05$. As not otherwise indicated data are presented as mean \pm standard deviation.

\section{Results}

A total of 73 patients ( 29 female, 44 male, average age 48.2 years, \pm 16.9 years) met inclusion criteria and were enrolled. 28 patients (38.3\%, 20 female, 8 male) suffered from SAH, 25 patients $(34.3 \%, 3$ female, 22 male) from TBI, 13 patients $(17.8 \%, 4$ female, 9 male) from other types of ICH and finally 7 patients $(9.6 \%, 2$ female, 5 male) from cerebral ischemia.

11 patients (15.1\%) showed adequate defecation according to the definition given above (group "adequate defecation"). 4 patients in this group were female ( $13.8 \%$ of all female patients), 7 male ( $15.9 \%$ of all male patients). 62 patients (84.9\%) were assigned to group "inadequate defecation". A period of insufficient bowel movement on at least seven consecutive days (group "long period with inadequate defecation") was detected in 28 patients $(46.8 \%$ of the patients of group "inadequate defecation, $38.4 \%$ of all patients respectively). 8 patients in this group were female (27.6\% of all female patients), 20 male ( $45.5 \%$ of all male patients).

\section{Defecation and ICP}

The initially established ICP probe was removed as soon as possible after reaching a stable situation regarding ICP values to prevent infectious complications. Therefore, a continuous recording of ICP values during the first ten days of ICU stay was available in only 56 patients. During this period, inadequate defecation for more than three consecutive days occurred in 49 of these patients. 7 patients showed a normal defecation pattern. Within the patients with inadequate defecation pattern two patients showed extremely elevated mean daily ICP values on day $9(56.31 \mathrm{mmHg}$ and $36.46 \mathrm{mmHg})$ and 10 (106.84 $\mathrm{mmHg}$ and $85.07 \mathrm{mmHg}$ ) due to multiple infarction as a consequence of severe cerebral vasospasm following SAH and an intracerebral bleeding after installing an external ventricular drainage respectively with deleterious prognosis. Therefore, both patients were excluded from the calculations. Table 1 shows the development of the mean daily ICP value over the time comparing both groups. A significant difference of mean daily ICP values was not seen throughout the whole observation period.

\begin{tabular}{|l|l|l|l|l|l|}
\hline & $\begin{array}{l}\text { Mean Group } \\
\text { "Inadequate } \\
\text { defecation" } \\
\text { (mmHg) }\end{array}$ & $\begin{array}{l}\text { Mean Group } \\
\text { "Adequate } \\
\text { defecation" } \\
\text { (mmHg) }\end{array}$ & $\begin{array}{l}\text { MD } \\
\text { (mmHg) }\end{array}$ & $\mathbf{9 5 \% - C l}$ & p-value \\
\hline Day 1 & 10.43 & 8.35 & 2.08 & $-2.67 ; 6.84$ & 0.327 \\
\hline Day 2 & 11.73 & 12.47 & -0.74 & $-3.77 ; 2.29$ & 0.598 \\
\hline Day 3 & 11.63 & 11.92 & -0.29 & $-3.02 ; 2.44$ & 0.815 \\
\hline Day 4 & 10.86 & 11.44 & -0.58 & $-3.91 ; 2.73$ & 0.694 \\
\hline Day 5 & 11.10 & 11.02 & 0.08 & $-2.98 ; 3.14$ & 0.954 \\
\hline Day 6 & 11.43 & 11.02 & 0.41 & $-1.56 ; 2.37$ & 0.663 \\
\hline Day 7 & 10.95 & 10.66 & 0.29 & $-1.72 ; 2.30$ & 0.760 \\
\hline Day 8 & 11.68 & 10.50 & 1.18 & $-0.76 ; 3.11$ & 0.212 \\
\hline Day 9 & 11.08 & 10.56 & 0.52 & $-1.87 ; 2.90$ & 0.644 \\
\hline Day 10 & 11.32 & 9.29 & 2.03 & $-0.50 ; 4.56$ & 0.109 \\
\hline
\end{tabular}

Table 1: Mean daily ICP values until day 10 after admission to the ICU. MD: Mean Difference; CI: Confidence Interval.

\section{Defecation and ICU therapy}

Patients classified into group "adequate defecation" had to be ventilated mechanically for an average of 8.8 days, whereas "inadequate defecation" group patients were ventilator-dependent for 15.9 days. This was a statistically significant mean difference of 7.1 days (95\%-CI 4.4; 9.7). The shortest ventilation period was 5 days in group "adequate defecation" and 3 days in group "inadequate defecation", the longest period 13 days vs. 42 days respectively. The mean length of ICU stay was 16.5 days in group "adequate defecation" and 24.8 days in group "inadequate defecation". This was also a statistically significant mean difference of 8.4 days (95\%-CI $4.7 ; 12.0$ ).

\section{Defecation and analgosedation}

Propofol, midazolam, ketamine and if necessary methohexital on top were given for sedation and sufentanil was used for analgesia. The 
Citation: Kieninger M, Finzel T, Zech N, Seemann M, Bele S, et al. (2015) Frequency of Disturbed Defecation Pattern in Neurosurgical Critically III Patients and Influence on Intracranial Pressure and Intensive Care Treatment. J Anesth Clin Res 6: 588. doi: $10.4172 / 2155-6148.1000588$

Page 3 of 5

mean cumulative dose was significantly higher in the group "inadequate defecation" for all drugs (Table 2).

\begin{tabular}{|l|l|l|l|l|l|}
\hline & $\begin{array}{l}\text { Cumulative } \\
\text { dose Group } \\
\text { "inadequate } \\
\text { defecation" } \\
\text { (g) }\end{array}$ & $\begin{array}{l}\text { Cumulative } \\
\text { dose Group } \\
\text { "adequate } \\
\text { defecation" } \\
\text { (g) }\end{array}$ & MD (g) & $\mathbf{9 5 \%}$ Cl & p-value \\
\hline Propofol & 24.06 & 12.91 & 11.15 & $2.59 ; 19.73$ & 0.012 \\
\hline Midazolam & 3.81 & 1.12 & 2.69 & $1.48 ; 3.89$ & $<0.001$ \\
\hline Ketamine & 30.26 & 7.72 & 22.54 & $\begin{array}{l}10.68 ; \\
34.40\end{array}$ & $<0.001$ \\
\hline Methohexita & 4.98 & 0 & 4.98 & $2.15 ; 7.82$ & 0.001 \\
\hline Sufentanil & 0.020 & 0.008 & 0.012 & $\begin{array}{l}0.007 ; \\
0.017\end{array}$ & $<0.001$ \\
\hline
\end{tabular}

Table 2: Cumulative dose of drugs used for analgosedation. MD: Mean Difference; CI: Confidence Interval.

\section{Defecation and circulatory support}

For circulatory support norepinephrine, dobutamine or epinephrine were given if necessary. The mean cumulative dose was significantly higher in group "inadequate defecation" for norepinephrine but not for dobutamine or epinephrine despite a tendency towards higher doses for both agents in this group (Table 3).

\section{Long period of obstipation and ICP}

A noticeable number of 28 patients showed at least once an episode of insufficient bowel movement for at least seven consecutive days (group "long period with inadequate defecation").

\begin{tabular}{|l|l|l|l|l|l|}
\hline & $\begin{array}{l}\text { Group } \\
\text { "inadequate } \\
\text { defecation" } \\
\text { Cumulative } \\
\text { dose }(\mathbf{m g})\end{array}$ & $\begin{array}{l}\text { Group } \\
\text { "adequate } \\
\text { defecation" } \\
\text { Cumulative } \\
\text { dose }(\mathbf{m g})\end{array}$ & $\begin{array}{l}\text { MD } \\
\mathbf{( m g )}\end{array}$ & $\mathbf{9 5 \%} \mathbf{C l}$ & p-value \\
\hline Norepinephrine & 192.2 & 106.2 & 86.0 & $13.7 ; 158.3$ & 0.021 \\
\hline Dobutamine & 105.8 & 72.7 & 33.1 & $\begin{array}{l}-104.1 ; \\
170.5\end{array}$ & 0.615 \\
\hline Epinephrine & 10.4 & 0.2 & 10.2 & $5.3 ;-0.4$ & 0.058 \\
\hline
\end{tabular}

Table 3: Cumulative dose of catecholamines. MD: Mean Difference; CI: Confidence Interval.

\begin{tabular}{|c|c|c|c|c|c|c|c|c|c|c|c|c|c|}
\hline \multirow[t]{2}{*}{ Patient number } & \multicolumn{13}{|c|}{ Mean daily ICP $(\mathrm{mmHg})$} \\
\hline & Day 1 & 2 & 3 & 4 & 5 & 6 & 7 & 8 & 9 & 10 & 11 & 12 & 13 \\
\hline 3 & 12.4 & 15.4 & 15.7 & 14.1 & 13.2 & 13.8 & 12.4 & 12.1 & & & & & \\
\hline 6 & 3.7 & 6.8 & 7.5 & 7.1 & 9.9 & 7.2 & 7.6 & & & & & & \\
\hline 9 & 11.6 & 9.9 & 9.1 & 10.3 & 10.9 & 12.9 & 13.1 & 16.1 & 24.6 & & & & \\
\hline 25 & 12.8 & 12.1 & 10.4 & 10.9 & 11.9 & 11.0 & 12.5 & & & & & & \\
\hline 26 & 8.6 & 17.1 & 17.1 & 20.4 & 16.9 & 17.3 & 15.6 & 17.7 & & & & & \\
\hline 27 & 1.0 & 7.0 & 7.7 & 6.3 & 5.0 & 2.9 & 3.1 & & & & & & \\
\hline 35 & 14.0 & 13.6 & 11.6 & 9.4 & 9.8 & 11.4 & 11.3 & 12.1 & 11.4 & 12.5 & 10.5 & 11.3 & 10.1 \\
\hline 37 & 18.4 & 16.1 & 17.0 & 17.0 & 15.8 & 15.1 & 18.5 & 15.1 & & & & & \\
\hline 39 & 11.4 & 8.4 & 11.0 & 11.0 & 9.2 & 8.9 & 9.9 & 11.6 & & & & & \\
\hline 40 & 18.6 & 16.2 & 13.0 & 12.0 & 12.6 & 12.6 & 11.9 & 12.2 & 10.1 & 13.2 & & & \\
\hline 42 & 29.0 & 10.8 & 13.5 & 14.7 & 16.3 & 14.9 & 13.6 & 14.8 & 20.9 & & & & \\
\hline 46 & 20.1 & 21.1 & 23.8 & 24.2 & 25.4 & 24.4 & 23.1 & & & & & & \\
\hline 51 & 16.0 & 19.4 & 15.0 & 8.9 & 7.3 & 6.0 & 9.0 & 12.6 & 8.2 & 9.9 & 4.5 & 5.3 & 5.2 \\
\hline 53 & 11.5 & 14.9 & 13.9 & 14.1 & 14.5 & 16.1 & 17.3 & 22.3 & 20.8 & 17.8 & & & \\
\hline 59 & 3.9 & 5.0 & 7.1 & 10.2 & 12.4 & 9.3 & 6.3 & 7.8 & 6.0 & & & & \\
\hline 70 & 9.6 & 9.6 & 9.0 & 5.0 & 6.6 & 6.6 & 9.5 & & & & & & \\
\hline 73 & 3.1 & 5.5 & 8.8 & 6.1 & 7.6 & 15.6 & 14.0 & & & & & & \\
\hline
\end{tabular}

Table 4: Mean daily ICP in patients with a long period without adequate defecation. Day 1 is the first day of this period starting one day after last sufficient defecation. 
Citation: Kieninger M, Finzel T, Zech N, Seemann M, Bele S, et al. (2015) Frequency of Disturbed Defecation Pattern in Neurosurgical Critically III Patients and Influence on Intracranial Pressure and Intensive Care Treatment. J Anesth Clin Res 6: 588. doi: $10.4172 / 2155-6148.1000588$

Page 4 of 5

A continuous recording of the ICP values during these episodes existed in 19 patients out of this group. Again two patients were excluded due to deleterious prognosis. Thus 17 patients remained in which the development of the mean daily ICP values during this long period without adequate defecation could be compared (Table 4). We only saw a slight increase of $1.07 \mathrm{mmHg}(12.10 \mathrm{mmHg}, \pm 7.13 \mathrm{mmHg}$ on day $1 \mathrm{vs.} 13.17 \mathrm{mmHg}, \pm 6.18 \mathrm{mmHg}$ on the last day) in mean daily ICP. Two patients (number 35 and 51) had a remarkably long period of 13 consecutive days without adequate defecation. In these two patients the mean daily ICP even declined and was lower on the last day of this episode than at the beginning.

\section{Discussion}

The present study shows that an insufficient defecation pattern is a common problem in critically ill neurosurgical patients as only $15.1 \%$ of all patients showed adequate defecation at least every third day during the observation period. Interestingly even longer periods without adequate defecation were not associated with elevated mean daily ICP values compared to patients showing an adequate defecation pattern. However, patients with regular bowel movement had to be ventilated and treated significantly shorter on ICU.

In literature the incidence of constipation varies from $16 \%$ to $84 \%$ in critically ill patients [8-10,12-15]. Main reasons for this variance might be the inhomogeneity of the study populations and the lack of a general definition of regular bowel movement. We recently examined the defecation pattern within the first 5 days after ICU admission in neurosurgical intensive care patients comparing a group where laxatives and physical measures had been applicated in a standardized manner after implementation of a SOP to a group where the pro motility measures had been ordered without any schedule merely according to the attending physician's estimation. In this study the number of patients showing adequate defecation was over all low with $24 \%$ in the intervention group and $8.3 \%$ in the control group respectively [11]. In concordance to these previous findings the percentage of patients with regular defecation was $15.1 \%$ in the present study.

It might be assumed that the absence of defecation leads to elevated IAP levels over time. The association between an elevated IAP and rising ICP values has been described repeatedly [1-3, 16-19]. However, it is difficult to predict the development of IAP in the individual critically ill patient [20-23]. In our previous study we had not seen higher ICP levels in the group showing an inadequate defecation pattern. However, in the preceding study we only observed the first five days after admission to the ICU. We supposed that this short period of time was not long enough to find a detectable effect of inadequate defecation pattern on the ICP levels as probably this period was too short to develop a relevant increase in IAP due to lack of defecation. This was the main reason for initiating the present study, now examining the whole time of intensive care treatment. Although the initially established ICP probes were removed as soon as possible in order to prevent infectious complications we were able to analyze data of 56 patients who had a continuous ICP measurement during the first ten days of ICU stay. Once again no difference was seen between the mean ICP values in the patients showing an adequate defecation pattern compared to those whose bowel movement was insufficient. Even in patients with a remarkably long period of at least seven consecutive days without adequate defecation no relevant increase of ICP was detected. These findings seem to be surprising, but probably only a manifest abdominal compartment syndrome can induce a relevant ICP elevation as several case reports and a small patient series suggest. Unfortunately, the IAP values were not recorded regularly in the study population what in fact is a limitation of our present study. Therefore, it is impossible to rule out that even in cases with an extremely long period without defecation an increase in ICP was not seen simply because there was no relevant elevation in IAP.

However, another result of the current study may provide a different interpretation approach. The mean cumulative dose of all sedatives and sufentanil was significantly higher in the group "inadequate defecation". Correspondingly norepinephrine that was used as first line vasopressor also had to be given in higher dosage when defecation pattern was inadequate. These findings are in concordance to literature where an association between sedatives, analgesics (especially opioids) and vasopressors and constipation is described [5,7,24-26]. All these drugs are well-known to impair gut motility in a dose-dependent manner. Therefore, the higher dosage of the applied drugs might be the reason for the disturbed defecation pattern. On the other hand, however, the situation could be interpreted inversely as well so that a deeper analgosedation could have been necessary to control borderline ICP levels in patients with inadequate defecation pattern. Deep analgosedation is an elementary aspect of conservative treatment of elevated ICP. Thus higher dosages of vasopressors could have been necessary due to deeper analgosedation. The observed prolonged ventilator dependency and duration of ICU therapy in patients with disturbed bowel movements seems also to be in line with this interpretation. In this context prolonged respirator therapy could have been necessary because of longer and deeper analgosedation. Furthermore, the weaning phase from the respirator is often associated with a moderate hypercapnia. It is likely that a reduction of the respirator therapy invasivity allowing spontaneous breathing was not possible in those patients with inadequate defecation pattern as the resulting moderate hypercapnia would have led to an excess of ICP thresholds.

In summary, the present study can lead to different interpretation approaches and is not able to draw a chain of causation free of doubt. Seen from a pure clinical standpoint efforts for optimizing bowel movements in critically ill patients with acute severe cerebral disorders seem to be justified as we have seen a correlation between an insufficient defecation pattern and a longer duration of ventilator dependency and ICU treatment. To be able to answer the open questions we are in need of larger prospective studies with regular measurement of IAP and inclusion of protocol-based strategies for optimizing bowel movement and defecation in critically ill neurosurgical patients.

\section{Conclusion}

Critically ill patients with an acute severe cerebral disorder often show an inadequate defecation pattern. This, however, seems not to be associated with elevated ICP levels even if patients do not show an adequate bowel movement for seven consecutive days or even longer. On the other hand, higher doses of drugs for analgosedation and circulatory support are necessary in these patients. In addition, compared to patients with an adequate defecation pattern those patients show a prolonged ventilator dependency and are in need of a longer ICU treatment. 
Citation: Kieninger M, Finzel T, Zech N, Seemann M, Bele S, et al. (2015) Frequency of Disturbed Defecation Pattern in Neurosurgical Critically III Patients and Influence on Intracranial Pressure and Intensive Care Treatment. J Anesth Clin Res 6: 588. doi: $10.4172 / 2155-6148.1000588$

Page 5 of 5

\section{Conflict of Interest Statement}

Martin Kieninger, Tobias Finzel, Nina Zech, Milena Seemann, Sylvia Bele and Holger Künzig declare that they have no conflict of interest.

\section{References}

1. Lauerman MH, Stein DM (2014) Multicompartment management of patients with severe traumatic brain injury. Curr Opin Anaesthesiol 27: 219-224.

2. Rickels E (2009) Monitoring intracranial pressure. Indication, limits, practice. Anaesthesist 58: 398-404.

3. Ben-Haim M, Mandeli J, Friedman RL, Rosenthal RJ (2000) Mechanisms of systemic hypertension during acute elevation of intraabdominal pressure. J Surg Res 91: 101-105.

4. Nguyen T, Frenette AJ, Johanson C, Maclean RD, Patel R, et al. (2013) Impaired gastrointestinal transit and its associated morbidity in the intensive care unit. J Crit Care 28: 537.

5. Gacouin A, Camus C, Gros A, Isslame S, Marque S, et al. (2010) Constipation in long-term ventilated patients: associated factors and impact on intensive care unit outcomes. Crit Care Med 38: 1933-1938.

6. van der Spoel JI, Oudemans-van Straaten HM, Kuiper MA, van Roon EN, Zandstra DF, et al. (2007) Laxation of critically ill patients with lactulose or polyethylene glycol: a two-center randomized, double-blind, placebocontrolled trial. Crit Care Med 35: 2726-2731.

7. van der Spoel JI, Schultz MJ, van der Voort PH, de Jonge E (2006) Influence of severity of illness, medication and selective decontamination on defecation. Intensive Care Med 32: 875-880.

8. Nassar AP Jr, da Silva FM, de Cleva R (2009) Constipation in intensive care unit: incidence and risk factors. J Crit Care 24: 630.

9. Mostafa SM, Bhandari S, Ritchie G, Gratton N, Wenstone R (2003) Constipation and its implications in the critically ill patient. Br J Anaesth 91: 815-819.

10. Montejo JC (1999) Enteral nutrition-related gastrointestinal complications in critically ill patients: a multicenter study. The Nutritional and Metabolic Working Group of the Spanish Society of Intensive Care Medicine and Coronary Units. Crit Care Med 27: 1447-1453.

11. Kieninger M, Sinner B, Graf B, Grassold A, Bele S, et al. (2014) Standardized application of laxatives and physical measures in neurosurgical intensive care patients improves defecation pattern but is not associated with lower intracranial pressure. Crit Care Res Pract 2014: 367251.

12. Elpern EH, Stutz L, Peterson S, Gurka DP, Skipper A (2004) Outcomes associated with enteral tube feedings in a medical intensive care unit. Am J Crit Care 13: 221-227.
13. Mutlu GM, Mutlu EA, Factor P (2001) GI Complications in patients receiving mechanical ventilation. Chest 119: 1222-1241.

14. Guerra TL, Mendonça SS, Marshall NG (2013) Incidence of constipation in an intensive care unit. Rev Bras Ter Intensiva 25: 87-92.

15. Kao CH, ChangLai SP, Chieng PU, Yen TC (1998) Gastric emptying in head-injured patients. Am J Gastroenterol 93: 1108-1112.

16. Nagpal S, Halpern CH, Sims C, Calland JF, Gracias VH, et al. (2009) Decompressive laparotomy to treat intractable cerebral hypoxia. J Trauma 67: E152-155.

17. Dorfman JD, Burns JD, Green DM, DeFusco C, Agarwal S (2011) Decompressive laparotomy for refractory intracranial hypertension after traumatic brain injury. Neurocrit Care 15: 516-518.

18. Rizoli S, Mamtani A, Scarpelini S, Kirkpatrick AW (2010) Abdominal compartment syndrome in trauma resuscitation. Curr Opin Anaesthesiol 23: 251-257.

19. Vegar-Brozovic V, Brezak J, Brozovic I (2008) Intra-abdominal hypertension: pulmonary and cerebral complications. Transplant Proc 40: 1190-1192.

20. Vidal MG, Ruiz Weisser J, Gonzalez F, Toro MA, Loudet C, et al. (2008) Incidence and clinical effects of intra-abdominal hypertension in critically ill patients. Crit Care Med 36: 1823-1831.

21. Reintam A, Parm P, Kitus R, Kern H, Starkopf J (2008) Primary and secondary intra-abdominal hypertension--different impact on ICU outcome. Intensive Care Med 34: 1624-1631.

22. Malbrain ML, Chiumello D, Pelosi P, Bihari D, Innes R, et al. (2005) Incidence and prognosis of intraabdominal hypertension in a mixed population of critically ill patients: a multiple-center epidemiological study. Crit Care Med 33: 315-322.

23. Fruhwald S, Holzer P, Metzler H (2007) Intestinal motility disturbances in intensive care patients pathogenesis and clinical impact. Intensive Care Med 33: 36-44.

24. Patanwala AE, Abarca J, Huckleberry Y, Erstad BL (2006) Pharmacologic management of constipation in the critically ill patient. Pharmacotherapy 26: 896-902.

25. Schreiber D, Klotz M, Laures K, Clasohm J, Bischof M, et al. (2014) The mesenterially perfused rat small intestine: A versatile approach for pharmacological testings. Ann Anat 196: 158-166.

26. Fruhwald S, Scheidl S, Toller W, Petnehazy T, Holzer P, et al. (2000) Low potential of dobutamine and dopexamine to block intestinal peristalsis as compared with other catecholamines. Crit Care Med 28: 2893-2897. 